\title{
Non-syndromic primary maxillary peg central incisors with multiple wormian bones in a 6-year-old boy: an unusual presentation
}

\author{
M Hari Kumar, ${ }^{1}$ M Siva Kumar, ${ }^{2}$ Vishalakshi Siva Kumar, ${ }^{2}$ Sabitha Hari Kumar ${ }^{3}$
}

${ }^{1}$ Department of Oral Medicine and Oral Radiology, Rajas Dental College and Hospital, Tirunelvelli, Tamil Nadu, India ${ }^{2}$ Department of Maxillo Facial, Doctor Kamalkanadasan Dental Clinic, Chennai, Tamil Nadu, India

${ }^{3}$ Dental Department, Jeba Dental Clinic, Chennai, Tamil Nadu, India

\section{Correspondence to Dr M Hari Kumar,} drhari.omrd@gmail.com

Accepted 5 December 2015
CrossMark

To cite: Kumar $\mathrm{MH}$ Kumar MS, Kumar VS, et al. BMJ Case Rep Published online: [please include Day Month Year] doi:10.1136/ bcr-2015-211240

\section{DESCRIPTION}

The peg-shaped conical tooth is the supernumerary tooth most commonly found in the permanent dentition. It develops with root formation ahead of or at an equivalent stage to that of the permanent incisors and usually presents as a mesiodens. ${ }^{1}$

Tooth malformations such as conical incisors and conical canines are commonly seen in hypohidrotic ectodermal dysplasia males and may also occur in heterozygous females to a less severe degree. ${ }^{2}$

Wormian bones are small bones that are often found within the sutures and fontanelles of the skull. They are often considered to be a simple anatomical variation. Nonetheless, they are more commonly seen in patients with certain kinds of bone dysplasia such as cleidocranial dysostosis, pycnodysostosis, congenital hypothyroidism, rickets and osteogenesis imperfecta. These bones are very common and sometimes occur in high numbers in children even when there is no history of osteogenesis imperfecta, and they are usually considered to be a simple anatomical variant the mechanism of development of which is not entirely understood. ${ }^{3}$

In the present case, a 6 -year-old boy visited the oral medicine department for a routine dental check-up. His medical and surgical histories were unremarkable. On extraoral examination, there was no facial asymmetry seen. Physical examination revealed a moderately built boy, weighing $23 \mathrm{~kg}$ and $114 \mathrm{~cm}$ tall. Further physical examinations did not reveal any signs of disproportionate extremities. An intraoral examination revealed the presence of a complete primary dentition with good oral hygiene, and also showed the presence of peg-shaped primary maxillary right and left central incisors (figure 1). Since the presentation of these incisors were very unusual, the patient was advised to undergo an orthopantomogram, a lateral

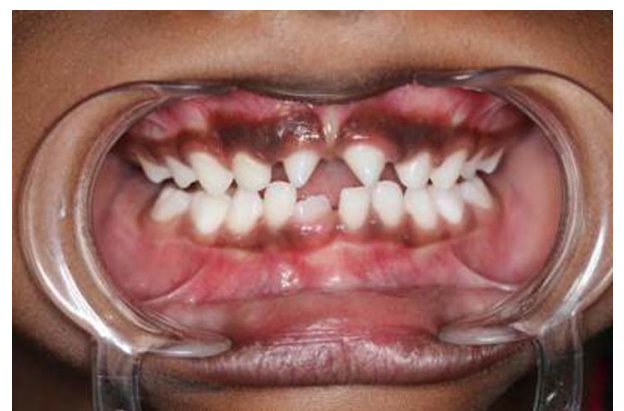

Figure 1 Intraoral examination showing presence of peg-shaped primary maxillary right and left central incisor.

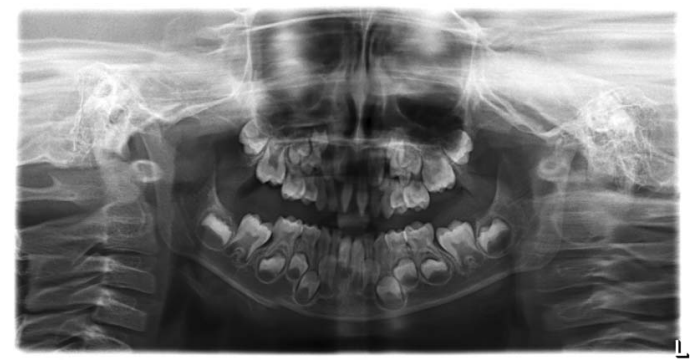

Figure 2 Orthopantomogram showing multiple tooth buds with peg-shaped primary central incisors.

cephalogram, an intraoral periapical (IOPA) radiograph and a maxillary occlusal radiographic view.

The orthopantomogram view showed multiple permanent tooth buds with peg-shaped primary central incisors (figure 2). The lateral cephalogram also showed multiple permanent tooth buds and peg-shaped primary central incisors with multiple wormian bones (figure 3).

The IOPA radiograph and maxillary occlusal radiographic view clearly showed a completely developed crown on the permanent left and right central incisors with peg-shaped crowns on the right and left primary central incisors, and also showed partial root resorption of the primary right and left central incisors (figure $4 \mathrm{~A}, \mathrm{~B}$ )

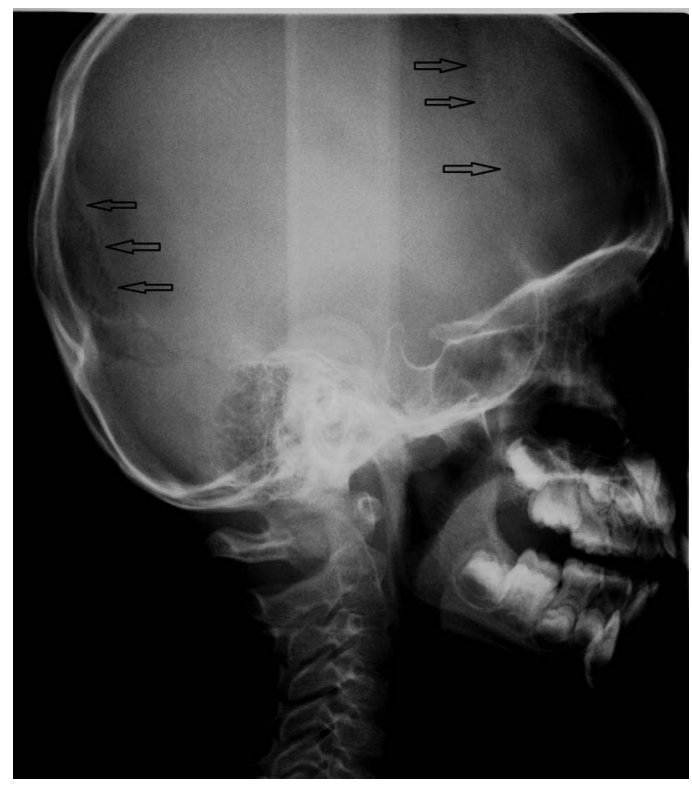

Figure 3 Lateral cephalogram showing multiple tooth buds and peg-shaped primary central incisors with multiple wormian bones. In this picture, the black arrows indicate the multiple wormian bones. 
Figure 4 (A) Intraoral periapical radiograph. (B) Maxillary occlusal radiographic view. Both the views clearly showing a completely developed crown on the permanent left and right central incisors, with a peg-shaped crown on the right and left primary central incisors, they also show partial root resorption of the primary right and left central incisors.
A

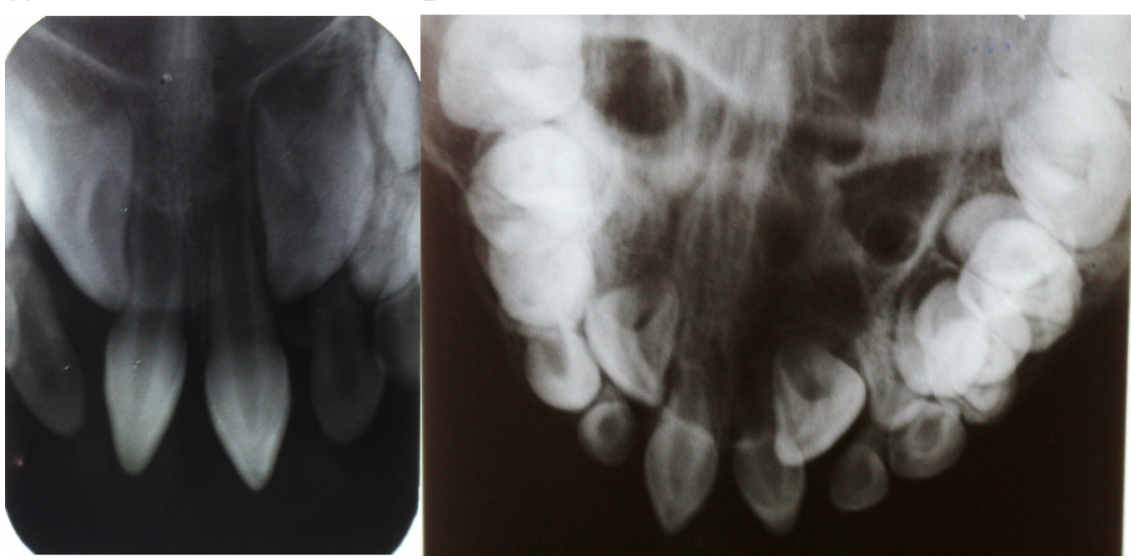

Genetic investigation was interrupted as the patient was originally from an underserved rural area near the town of Nagercoil in south India, and had to travel $21 \mathrm{~h}$ by bus to reach the nearest genetic reference centre. The patient's family members, including paternal and maternal relatives, were not

\section{Learning points}

- Peg-shaped primary central incisors are rare anomalies of tooth formation and are commonly associated with syndromes such as hypohidrotic ectodermal dysplasia. Presentation of non-syndromic primary maxillary peg central incisors is very rare and has not yet been documented in the medical literature.

- Wormian bones, also called supernumerary bones, may act as markers for anomalies such as cleidocranial dysostosis, pycnodysostosis, aplasia cutis congenita, chondrodysplasia punctata, congenital hypothyroidism, rickets, Hajdu-Cheney syndrome, Hallerman-Streiff syndrome and osteogenesis imperfecta. And sometimes it can also occur as the normal variant, where careful radiological evaluation with prenatal ultrasound can help in early diagnosis of this anomaly. available to participate in the genetic study. Thus, based on the available findings, the patient was diagnosed as having nonsyndromic primary maxillary peg central incisors with multiple wormian bones. Oral prophylaxis was performed along with diet counselling, and oral hygiene instructions were given. The peg-shaped primary central incisors were left untreated, as the patient's parents were unwilling to have him undergo further treatment. The patient was advised to have regular recall visits.

Contributors MHK and MSK contributed to diagnosis of the patient, concept of the paper, acquisition of data, and drafting, revision and final approval of the article. VSK contributed to diagnosis of the patient, concept of the paper, acquisition of data, and revision and final approval of the article. SHK contributed to diagnosis of the patient, concept of the paper, and drafting, revision and final approval of the article.

Competing interests None declared.

Patient consent Obtained.

Provenance and peer review Not commissioned; externally peer reviewed.

\section{REFERENCES}

1 Garvey MT, Barry HJ, Blake M. Supernumerary teeth-an overview of classification diagnosis and management. J Can Dent Assoc 1999:65:612-16.

2 Lexner MO, Bardow A, Hertz JM, et al. Anomalies of tooth formation in hypohidrotic ectodermal dysplasia. Int J Paediatr Dent 2007;17:10-18.

3 Marti B, Sirinelli D, Maurin L, et al. Wormian bones in a general paediatric population. Diagn Interv Imaging 2013;94:428-32.

Copyright 2015 BMJ Publishing Group. All rights reserved. For permission to reuse any of this content visit http://group.bmi.com/group/rights-licensing/permissions.

BMJ Case Report Fellows may re-use this article for personal use and teaching without any further permission.

Become a Fellow of BMJ Case Reports today and you can:

- Submit as many cases as you like

- Enjoy fast sympathetic peer review and rapid publication of accepted articles

- Access all the published articles

- Re-use any of the published material for personal use and teaching without further permission

For information on Institutional Fellowships contact consortiasales@bmjgroup.com

Visit casereports.bmj.com for more articles like this and to become a Fellow 